\title{
"Seja uma mulher vencedora!": particularidades de gênero e definições do sucesso na literatura de autoajuda ${ }^{1}$
}

Mayka Castellano

\section{Resumo}

Neste artigo, a partir da análise de discurso de inspiração pós-estruturalista, avalio um exemplar da literatura de autoajuda voltado para o sucesso feminino. A leitura do livro Marketing de B.A.T.O.M: atitudes que fazem da mulher uma vencedora, de Fádua Sleiman (2008), permite verificar a existência de determinadas demandas típicas do imaginário do sucesso contemporâneo, que incita a todos a serem vencedores, ao mesmo tempo em que fornece indicativos de que, ao se referirem especificamente às mulheres, esses livros apontam uma série de continuidades problemáticas relativas às questões de gênero e à inserção da mulher no mercado de trabalho.

\section{Palavras-Chave}

Autoajuda. Sucesso. Gênero.

Mayka Castellano I maykacastellano@gmail.com Pós-doutoranda no Programa de Pós-Graduação em Comunicação e Cultura da Escola de Comunicação da Universidade Federal do Rio de Janeiro - ECO/UFRJ, com bolsa de auxílio à pesquisa da Faperj. Doutora pela mesma instituição, na linha Mídia e Mediações Socioculturais.
A autoajuda é, hoje, um dos segmentos editoriais de maior sucesso no Brasil. A quantidade e a variedade de títulos do gênero disponíveis nas livrarias brasileiras impressionam. Mais do que um filão literário, no entanto, a autoajuda se tornou uma espécie de ethos, representação de aspectos morais e estéticos valorativos de uma determinada cultura (GEERTZ, 1978). É partindo dessa premissa que o presente artigo avalia um tipo específico de subjetividade que aparece com frequência no discurso propalado por esses livros: a mulher vencedora.

Versão feminina do vencedor (construção discursiva que ajuda a materializar boa parte das premissas presentes na literatura de autoajuda), a vencedora, além de incorporar todo 0 arsenal imagético associado ao sucesso contemporâneo - ligado, dentre outras coisas, à eficiência, à performance e à proatividade no trabalho (EHRENBERG, 1991; SENNETT, 2007) -, também assimila uma série de preceitos específicos relativos ao gênero feminino, em assuntos como os relacionamentos amorosos, as relações sociais, o cuidado com 0 corpo, a beleza e a maternidade. 
Embora me ampare em um corpus empírico mais vasto avaliado em minha tese de doutorado (SUPRIMIDO), neste artigo me dedico à análise do livro Marketing de B.A.T.O.M: atitudes que fazem da mulher uma vencedora (SLEIMAN, 2008).

Para a interpretação dos textos de autoajuda realizada no artigo, lanço mão da análise de discurso de inspiração pós-estruturalista, que privilegia 0 conteúdo e o contexto da linguagem e não sua estrutura. A ideia de discurso surge, aqui, associada às relações de poder específicas, historicamente constituídas, as quais ele engendra, e das noções particulares de verdade que atualiza (FOUCAULT, 1995; 1999; 2006). Ou seja, a partir da problematização de demandas da autoajuda associadas à figura da "mulher vencedora", construo minha argumentação a respeito dos modos de produção de subjetividade (ROSE, 1999; 2007; 2008) ligada à figura feminina na contemporaneidade.

\section{A mulher bem-sucedida}

Se utilizarmos a oferta de livros de autoajuda como termômetro para medir as principais aspirações dos sujeitos contemporâneos, não seria muito difícil avaliarmos o que, afinal, querem as mulheres. Elas querem um homem com quem possam construir um relacionamento amoroso estável. E elas também querem ficar magras e bonitas. A impressionante maioria dos títulos de autoajuda voltados especificamente para o público feminino gira em torno dessas duas temáticas, com forte predominância da primeira. É interessante a quase inexistência de livros desse filão dedicados especialmente aos homens. Aparentemente, os dilemas do coração são atributos exclusivos delas. Se os títulos que falam de sucesso e felicidade parecem ser unissex e trazem em seu bojo ensinamentos que servem, indistintamente, aos dois gêneros e às múltiplas identidades sexuais - embora usem o gênero masculino genérico em sua linguagem -, as obras destinadas ao aprimoramento da vida amorosa/ conjugal têm um público bastante definido: as mulheres heterossexuais.

A literatura de autoajuda surge no século XIX com títulos, hoje, considerados clássicos como Selfhelp, de Samuel Smiles (1859), e Como alcançar o sucesso, de Orison Swett Marden (1896), contexto em que podemos apontar a consolidação do mito do self-made man. É apenas no início do século $\mathrm{XX}$, no entanto, que as mulheres passam a ser protagonistas da literatura motivacional, ensejada por esse tipo de enquadramento sobre o que significaria uma vida "bem-sucedida". Até então, sua participação nesse imaginário era vicária, normalmente a partir de algum papel importante na vida de um homem de sucesso: a mãe zelosa, a esposa dedicada, a filha amorosa... De acordo com Micki McGee (2005), a ideia de que as mulheres deveriam, por conta própria, buscar o sucesso, atrelado a uma carreira que lhe garantisse não 
só 0 sustento, mas algum tipo de compensação pessoal, só vai aparecer de maneira clara a partir da década de 1960, com a publicação de duas obras seminais: Sex and the single girl, de Helen Gurley Brown (1962), e The feminine mystique, de Betty Friedan (1963).

0 livro de Brown, um best-seller à sua época, inaugura a contradição que, como veremos adiante, é uma das marcas indeléveis da autoajuda feminina. Embora afirmasse que as mulheres solteiras deveriam perseguir sua própria satisfação, e não necessariamente o casamento, ele sugeria que o trabalho poderia ser mais do que uma forma relativamente prazerosa de passar 0 tempo, mas, principalmente, o contexto ideal para se conhecer um homem:

Agora vamos nos desligar dos homens por um momento e falar sobre 0 seu trabalho. (Não se preocupe, nós vamos voltar a eles!). 0 que você faz das nove às cinco tem tudo a ver com os homens, de qualquer forma. Um trabalho é uma maneira de chegar a eles. Ele também fornece 0 dinheiro com 0 qual você irá se vestir para eles e decorar 0 seu apartamento para eles... E o mais importante: um trabalho dá à mulher solteira algo para ser. Uma mulher casada já é alguma coisa. Ela é esposa do banqueiro, a esposa do gangster, a esposa do cowboy, a esposa do estrangulador, a esposa do condutor (do bonde ou da orquestra)... A mulher solteira é conhecida pelo que ela faz e não pelo fato de pertencer a alguém (BROWN apud MCGEE, 2005, p. 39) 2 .

\section{Vencedora de batom: o lugar do feminino}

No livro Marketing de B.A.T.O.M: atitudes que

fazem da mulher uma vencedora, publicado em 2008, 46 anos depois da obra de Brown, Fádua Sleiman dedica um capítulo para cada característica que julga fundamental ao sucesso na vida profissional das mulheres e cujas iniciais formam a palavra batom: batalha, assertividade, testosterona, orientação profissional e "marketing de guerrilha feminino". A personagem principal da publicação é apresentada como a "mulher Batom", aquela que "trabalha a auto-estima, acredita na família, zela pela prosperidade do país, é próativa, amiga, companheira e deseja deixar para as próximas gerações frutos prósperos e sabedoria" (SLEIMAN, 2008, p. 107).

Em "Batalha", o discurso refere-se ao ambiente competitivo, marca do mundo atual. Se esta é uma realidade que extrapola o âmbito profissional, atingindo, também, as relações pessoais, familiares, 0 ambiente educacional, etc., a tática proposta pelo livro também não faz distinção entre as diferentes esferas: "No nosso cotidiano, seja na atividade social, profissional, familiar, no relacionamento humano, enfim, a todo instante, devemos empunhar as armas de que dispomos, na busca pela vitória" (SLEIMAN, 2008, p.

Tradução da autora. No original: Now we're going to turn off men for a while and talk about your job. (Don't worry, we'll get back to them!) What you do from nine to five has everything to do with men anyhow. $\mathrm{A}$ job is a way of getting to them. It also provides money with which to dress for them and dress up your apartment for them... Most importantly, a job gives a single woman something to be. A married woman already is something. She is the banker's wife, the gangster's wife, the wrangler's wife, the strangler's wife, the conductor's wife (streetcar or symphony)... A single woman is known by what she does rather than by whom she belongs to. 
17). Embora não deixe claro o que pretende dizer com vitória na "atividade familiar" ou no "relacionamento humano", o livro segue tratando esses domínios indistintamente: "Qualquer parceiro, seja ele chefe, namorado, colaborador, empregado de casa, amigo. Se não está bom, demita! Sim, você pode demitir ou tirar da sua vida pessoas que, de alguma forma, a incomodam" (2008, p. 32, grifo meu).

Como é comum nos livros de autoajuda, a autora entremeia um discurso subjetivo com dicas mais diretas sobre negócios de maneira geral e também incide em diversas contradições na construção dos argumentos, algo também corriqueiro nesse filão editorial. Depois de falar sobre a importância do empreendedorismo para os brasileiros, e antes de rechear o discurso com metáforas militares ${ }^{3}$, ela propõe uma tomada de consciência em relação ao papel social que deve ser desempenhado pelo empreendedor:

Questões de ordem ética se fazem cada vez mais urgentes. Como, por exemplo, saber se quem extrai a matéria-prima ou produz o insumo para o fornecedor está envolvido com a mão de obra infantil ou escrava. Esta é uma realidade que, devido ao acesso quase irrestrito à informação, revela-se com muita força no mundo atual. $E$ devemos estar atentos, inclusive denunciando-a.

Um bom produto satisfaz não apenas ao cliente final, mas também à sociedade. A busca de uma sociedade justa é uma preocupação do empreendedor de sucesso, algo que hoje ainda é considerado um diferencial, mas que a cada dia se tornará requisito indispensável para as empresas (SLEIMAN, 2008, p. 18-19).

Na literatura de autoajuda que surge no século XIX, a moral e o caráter aparecem como elementos fundamentais na consecução de uma vida de sucess $^{4}$. Nos livros publicados atualmente, a menção a essas questões é bastante rara. Em alguns momentos, no entanto, esses conceitos reaparecem, transformados em algo que pode ser usado como moeda de troca, a partir de um uso instrumental. "Se nosso passado ou presente nos condena, como liderar uma equipe altamente eficaz?", indaga Sleiman (2008, p. 20).

A contradição no discurso da autora também pode ser percebida na abordagem do tema sucesso versus fracasso. Ao mesmo tempo em que lista entre as características comportamentais que determinam o sucesso da mulher empreendedora a capacidade de lidar de forma positiva com 0 fracasso, entendido como uma possível "mola propulsora para se reerguer" (SLEIMAN, 2008, p. 106), na página seguinte, ela sugere como pensamento que "ajuda a firmar nossa mente e colabora com nosso crescimento" (Idem, p. 107) a frase "a dor e o fracasso são elementos estranhos à minha vida" (Idem).

Tais como: "Procure sempre sinalizar o foco do teu trabalho através de cores, bandeiras, flâmulas, post-its e outros recursos visuais. É o que fazem os generais que vão à frente de seus comandados. A flâmula que carregam é o significado maior do objetivo de guerra e o estímulo maior da batalha" (SLEIMAN, 2008: 21). 
No capítulo "Assertividade", a autora discorre sobre um período de sua juventude, quando morava na cidade de Mogi das Cruzes, interior de São Paulo. Sleiman conta que ela e a irmã eram proibidas pelo pai de passar em frente às 'repúblicas' ali instaladas, para não ficarem "na boca do povo" (2008, p. 25), "faladas" (Idem). Havia uma menina de sua escola, no entanto, que era "grande freqüentadora das fatídicas repúblicas dos alunos de engenharia e medicina" (2008, p.24), "conhecida de todos os rapazes" (2008, p.25). A história de Pamela, esse era o nome da moça, é contada no livro apenas para sermos informados de que hoje ela está "muito bem, obrigada. A Pamela está muitíssimo bem casada, é mãe de quatro filhos e é chamada de senhora" (2008, p. 25, grifo meu).

Em um livro voltado para o sucesso feminino publicado na primeira década do novo milênio, é bastante peculiar que 0 conceito de felicidade utilizado pela autora passe pelo bom casamento, pela maternidade e pela anacrônica distinção de ser chamada de senhora. É difícil estabelecer alguma relação entre 0 tema do capítulo e a história narrada. A própria autora reconhece que a passagem nada tem a ver com assertividade, o que, segundo ela, poderia ser atribuído à dificuldade que as mulheres têm de ir direto ao assunto. Quando resolve, de fato, falar sobre assertividade, porém, o exemplo que escolhe também é sintomático:

Não aceitem situações que a deixem angustiada, mesmo que sejam pequenas coisas. Quando a amiga pede emprestado aquele batom impor- tado que já está acabando, não se acanhe em dizer: - Fulana... estou com receio de que 0 batom esteja acabando, pode ser outro?" (SLEIMAN, 2008, p. 27).

Aparentemente, no mundo da autora, as aspirações das mulheres passam por serem chamadas de senhora e suas angústias giram em torno do fim de um batom importado. No capítulo "T de Testosterona", a obra embarca na concepção de self neuroquímico (ROSE, 2007) e propõe explicações sobre a ação dos hormônios na conduta das mulheres. Buscando compreender 0 comportamento feminino não através de suas próprias peculiaridades, mas a partir da falta, a autora discorre sobre os problemas associados a uma baixa quantidade dos bons hormônios (abundantes nos homens), como a serotonina e a própria testosterona ("Alguns cientistas a chamam de Super-T. Sugestivo, não? Nós traduzimos essa sigla como Super Tesão" [SLEIMAN, 2008, p.29]). Somos informados de que esse hormônio é o responsável pelos traços masculinos de personalidade, como "confiança, agressividade, tendência dominadora, espírito aventureiro, alto grau de competitividade e uma grande tendência ao risco" (2008, p. 29). 0 raciocínio é concluído com a constatação de que se as mulheres tivessem mais testosterona em seu organismo, se sairiam melhor em seus empreendimentos "familiares e empresariais" (2008, p. 29). Seriam mais homens, em suma. "Quem diria que um dia precisaríamos ter 'aquilo roxo' como uma das ferramentas para nos sobressairmos no ambiente de trabalho?" (2008, p. 28), indaga a autora. 
0 tom equivocado da explicação fisiológica fica evidente quando Sleiman afirma que é devido à influência do estrogênio que encontramos poucas mulheres em posições de chefia nas grandes empresas. Toda a construção social que, durante séculos, definiu papéis específicos para os diferentes gêneros e ajudou a projetar uma explícita desigualdade em termos de poder é descartada em nome da ação dos hormônios. Já as recentes transformações nesse quadro são descritas pela autora como "quando 0 homem passou a delegar a ela mais poder e responsabilidades" (2008, p. 43). Não foram, portanto, as mulheres que conquistaram mais direitos e espaço no mercado de trabalho, foram os homens que os "delegaram".

\section{As deusas do consumo}

Algumas ações de marketing voltadas para 0 público feminino são elogiadas pela autora ao longo dos capítulos. "Uma das mais inteligentes (...) dos últimos tempos" (SLEIMAN, 2008, p. 28) teria sido a da empresa Porto Seguro, que, consciente da falta de capacidade das mulheres em apreender distâncias, implantou a venda de aparelhos de GPS para seus clientes, estabelecendo pacotes especiais para elas, "que além de passarem a se familiarizar com a quilometragem, conseguiriam ficar de olho nos seus maridos" (2008: 29). Outra campanha digna de nota pela autora é a da Águas Ouro Fino, que lançou uma garrafa cor de rosa com a palavra "Woman" impressa.
Em um capítulo intitulado "Ken e Barbie", Sleiman exalta 0 que considera conquistas femininas, tais como a existência de eletrodomésticos voltados especificamente para elas e de carros com "design mais feminino" e com "espelho e luz no quebrasol” (2008: 88). 0 automóvel, a propósito, é apresentado como "bem de consumo que é o sonho de qualquer sexo ou classe no mundo" (Idem). A explicação para a referência aos clássicos bonecos da Mattel aparece no parágrafo final da seção: "0 mundo da Barbie retrata em muito o desejo da mulher contemporânea: chegar aos cinqüenta anos bonita, feliz, rica, independente, em seu próprio automóvel e com o Ken... sentado no banco ao lado!" (SLEIMAN, 2008, p. 89).

0 empoderamento contemporâneo da mulher, conforme a autora, passaria por sua atitude diante do consumo, tal como propõe 0 chamado pós-feminismo (McR0BBIE, 2006). De acordo com Freire Filho (2007), a crítica pós-feminista se notabilizou pelo empenho em superar os "dogmas" e o "puritanismo" do feminismo dos anos 1970, que se ressentia por uma espécie de fracasso em conquistar maior ressonância popular - sua "carrancuda ideologia antibeleza e antimoda intimidaria, depreciaria e afastaria a maior parte das mulheres" (idem, p. 119). Em vez de rejeitar os significantes e as atividades da feminilidade tradicional e de se engajar em atividades políticas mais diretas, o pósfeminismo verificado a partir dos anos 1990 passa a enxergar resistência e ativismo em práticas corriqueiras de consumo. 
"Usar batom não é mais repulsivo, e noções de identidade se distanciaram de um eixo racional/moral e são muito mais profundamente informadas por idéias de performance, estilo e desejo" (Brunsdon, 1997: 85). De maneira descontraída, as pós-feministas enfatizam a importância das escolhas individuais de estilo de vida e dos prazeres e poderes proporcionados pelo engajamento, devidamente habilitado, com os ingredientes básicos da indústria da feminilidade (FREIRE FILHO, 2007, p. 120).

Alinhados aos pressupostos do pós-feminismo, os argumentos apresentados no livro analisado neste artigo indicam que a independência feminina deve ser buscada basicamente em atividades como dirigir o próprio carro, comprar os próprios bens, bancar seu luxo - afinal, elas "admitem o gosto pelo luxo e pelas marcas caras, mantendo sempre entre seus pertences algum produto de alto valor, pelo simples fato de poder 'exibir' às pessoas" (SLEIMAN, 2008, p. 54). 0 apego das mulheres ao consumo aparece na retórica do aconselhamento desde os tempos das histórias rags-to-riches ${ }^{5}$, narrativas que contribuíram para a gênese do mito do self-made man nos Estados Unidos, berço do atual imaginário do sucesso (CATANO, 2001; DECKER, 1997).

Naquele contexto, a associação entre mulheres e consumo aparecia principalmente através das esposas esbanjadoras, que funcionavam como empecilho à prosperidade do marido.
Hoje, com a prerrogativa de decidir sobre a compra de produtos para a casa e também de influenciar as escolhas de parceiros e filhos, as mulheres são apresentadas por Sleiman como "deusas do consumo" (SLEIMAN, 2008, p. 61). "Homens são de Marte. Mulheres são do Shopping" é o título do capítulo dedicado exclusivamente a avaliar esse tipo controverso de empoderamento.

Além de tecer comentários gerais sobre a situação da mulher na contemporaneidade, Sleiman concentra-se em aconselhar as leitoras que atuam especificamente na área de marketing e vendas:

A mulher BATOM precisa ter a mente orientada $100 \%$ ao marketing. Respirar estratégias de sucesso, lucro e receita o tempo todo, em todos os lugares. Este é o marketing de guerrilha feminino. Então vamos à luta! Separe suas armas, ou meIhor, seus BATONS mais eficazes e fique atenta às seguintes dicas (SLEIMAN, 2008, p. 36).

As dicas listadas a seguir vão desde mensagens diretas como "Mantenha sua equipe uniformizada. Use 0 logotipo nas roupas e estimule seus funcionários a usarem, mesmo fora do seu horário de trabalho" (2008, p. 42); "use sempre palavras que influenciem positivamente as pessoas, tais como sucesso, agradável, poderoso, presente, maravilhoso, positivo, agradável, brilho" (Idem),

Os contos rags-to-riches (em tradução literal, algo como "dos trapos à riqueza") tratam de casos em que indivíduos saem de uma situação de extrema pobreza e alcançam fortuna e notoriedade. Esse tipo de narrativa é bastante popular nos Estados Unidos desde a época da colonização, mas ganhou destaque a partir de meados do século XIX, com as novelas escritas por Horatio Alger, do estado de Massachusetts, que contavam trajetórias de jovens pobres desde sua dura realidade no início da vida até 0 conforto trazido pelo enriquecimento e pela ascensão social. 0 primeiro de mais de cem livros publicados pelo autor foi Ragged Dick, de 1867. Todas as histórias têm como pano de fundo a valorização de aspectos como trabalho duro, coragem, determinação, esforço e honestidade, embora boa parte dos desfechos seja garantida graças à sorte deflagrada em eventos fortuitos. Ao final, além da prosperidade financeira, os protagonistas são alçados à personalidade de sua região e ganham 0 reconhecimento de todos, em uma típica materialização do sonho americano (CATANO, 2001; DECKER, 1997). 
até conselhos mais subjetivos, como "respire vendas o tempo todo, mesmo que as outras mulheres te achem uma chata" (2008, p. 40).

Ao analisarem a concorrência por uma boa colocação no trabalho, alguns livros sugerem que as mulheres disputam as vagas apenas com outras mulheres. A competitividade, tão anunciada, e muitas vezes celebrada, nesses livros, é interpretada nesse segmento como se fosse uma característica particular do sexo feminino. A explicação, como de costume, passa pela necessidade primitiva de disputar um bom parceiro. Desde os tempos das cavernas, as mulheres precisam se digladiar para conseguir o melhor partido, isso explicaria a falta de solidariedade entre elas. É relevante que, mesmo em publicações escritas por mulheres, uma série de estereótipos associados ao gênero seja reafirmada. A falta de controle, por exemplo, é uma constante: "Ao ser confrontada, a mulher tende a racionalizar como disputa pessoal, vê perigo eminente na disputa por um cargo, por um macho ou até pela relação com uma pessoa de cargo superior" (SLEIMAN, 2008, p. 68 , grifo meu), assim como a atitude histérica e a falsidade, presentes na descrição de um encontro entre mulheres: "Somos um bando de gralhas. Gritinhos, beijinhos, chamados de querida, elogios, muitos deles falsos. Todas falando ao mesmo tempo, cada vez mais alto, para cobrir o som da mesa ao lado" (2008, p. 69).

A autora também lança mão de uma das distinções mais comumente associadas ao universo feminino: o uso distinto das emoções. "Dá pra notar que este livro foi escrito com o coração: 0 órgão vital pelo qual circulam somente a verdade e a transparência durante nossa existência" (SLEIMAN, 2008). Se as atitudes dos homens são pautadas, sobretudo, por cálculos mentais e uso predominante da razão, no caso das mulheres as emoções seriam o preponderante. Se, como pude verificar em minha pesquisa de doutorado, as principais demandas dos mais importantes títulos de autoajuda focados na questão do sucesso apareciam através de conceitos como autonomia e responsabilidade, no caso da autoajuda voltada para mulheres, é outro termo que ganha força: 0 controle. A mulher vencedora precisa, antes de tudo, se controlar. Controlar as emoções, grandes vilãs às quais as mulheres são associadas de maneira sistemática - controlar, nesse sentido, o nível de autoestima, a insegurança, a raiva, a inveja, os ciúmes. Controlar os gastos, afinal, as mulheres são as deusas do consumo, como vimos anteriormente, mas "vermelho, só no esmalte, não no saldo bancário", alerta (SLEIMAN, 2008, p. 80). Controlar o peso - o que também é uma forma de autocontrole. Controlar as relações amorosas para que deságuem no destino desejado: o bom casamento. Controlar o marido, nem que seja com o GPS oferecido pela Porto Seguro. Controlar os filhos e a dinâmica da casa e daí por diante. A mulher descontrolada, assim, é a melhor representação da mulher fracassada ${ }^{6}$.

A partir da leitura de diversos títulos e da análise específica deste livro, fica evidente que a literatura 
de autoajuda voltada para as mulheres torna ainda mais explícita a contradição como marca deste filão editorial. Embora reconheçam a existência de um novo momento vivido pelas mulheres, e proponham a adoção de comportamentos condizentes com esses novos papéis (associados a uma maior participação feminina em todas as esferas de poder), tais livros ainda alimentam uma série de estereótipos associados ao gênero, sobretudo os vinculados aos arranjos familiares. A profissão da mulher, de acordo com o discurso apresentado por essas obras literárias, deve ser pensada sempre em tensão com a importância que desempenha em sua vida o relacionamento afetivo heterossexual. É interessante, nesse sentido, observar como a heteronormatividade está presente nesses livros. Em momento algum, nenhum dos oito livros ${ }^{7}$ analisados para minha tese cogitou a possibilidade de 0 relacionamento amoroso do leitor envolver pessoas do mesmo sexo. No caso do filão feminino, isso ainda é mais evidente.

Ao analisar as revistas femininas, em especial a Nova, José Luiz Aidar Prado (2013) avalia o que chama de convocações biopolíticas dos artefatos midiáticos. 0 pesquisador argumenta $o$ quão enquadrado em um padrão muito específico estão os modelos de feminino apresentados pela publicação, o que corrobora com o que vimos argumentando a respeito dos livros de autoajuda:

Nas diversas colunas, no editorial, nas reportagens, nos anúncios, a leitora é convocada a se tornar sujeito desse discurso da mulher ativa, não submissa, embora um exame mais detido nos revelasse que essa submissão, se negada num primeiro momento, mais explícito, é devolvida num segundo, pois nem toda atividade cabe nesse discurso. Alguns modelos de atividade feminina estão fora dessa identidade da mulher de Nova. Ela não pode ser gorda, queer,

Em um artigo em que analisa a reprodução de alguns estereótipos na autoajuda feminina, Brunelli (2012) cita títulos de capítulos do livro Mulher em primeiro lugar: mãe de família ensina como cuidar da família, manter a boa forma e ser feliz no casamento, de Kathryn Sansone, publicado no Brasil pela Sextante: "Por esse subtítulo notamos que o discurso de autoajuda também associa às mulheres os mesmos temas de sempre: cuidados com a família (maridos e filhos) e com a beleza. Alguns dos títulos das seções do livro também se referem à mesma temática. Por exemplo, sobre o tema da beleza temos: "Inclua a malhação na rotina diária"; "Mantenha-se em dia com o básico da beleza"; sobre o tema do casamento, há seções como: "Demonstre admiração por seu marido"; "Resgate a sensualidade dos tempos de namoro"; por fim, vejamos algumas seções sobre o tema da família: "Reúna a família"; "Crie um lar seguro"; "Faça das refeições um momento de alegria"; "Ensine as crianças a organizar a própria vida” (BRUNELLI, 2012: 113).

Meu corpus empírico contou com livros de autoajuda que tivessem como principal propósito o aconselhamento do leitor no sentido da consecução de uma vida vitoriosa, ou que repelissem explicitamente comportamentos caracterizados como típico dos fracassados, o que, muitas vezes, se manifestava no próprio título das obras, em palavras-chave como "vencer", "vitória", "vencedor", "sucesso", "fracassado", "fracasso", "derrota" e suas múltiplas variações, optei pela seleção a partir do critério de "mais vendidos". Depois de descartar obras que tratavam de assuntos muito restritos (tais como "oratória de vencedor" e "vencedor nas vendas"), acabei adquirindo um total de 47 livros. A partir desta primeira seleção, cheguei ao número de 26 exemplares, que foram lidos de maneira mais aprofundada. Ao final dessa fase da pesquisa, cheguei ao número final de oito livros, que foram analisados com maior profundidade na tese. São eles: os dois clássicos do século XIX Ajude-se (de Samuel Smiles, 2012) e Como alcançar o sucesso (de Swett Marden, 2011), e os contemporâneos S.O.S Sujeito ou Sujeitado: definindo seu sucesso ou seu fracasso (de Marisa Urban, 2010); Só é fracassado quem quer (de Thomas Morgan, 1989); A essência dos vencedores (de Giclér Regina, 2010) e Você é insubstituivel: este livro revela a sua biografia (de Augusto Cury, 2002); Filho rico, filho vencedor (de Robert Kiyosaki, 2001) e o livro que serve de objeto a este artigo: Marketing de B.A.T.O.M. - Atitudes que fazem da mulher uma vencedora (SLEIMAN, 2008). 
tímida, socialista, detestar maquiagem, ser despreocupada com a moda ou politizada demais (PRAD0, 2013, p. 53).

Notamos na perspectiva apontada por Prado (2013) a mesma dubiedade de discurso em relação ao papel da mulher na sociedade hoje, o que é indicativo da coexistência de bemvindas mudanças e incômodas permanências. A proximidade entre os discursos presentes em revistas femininas e em livros de autoajuda voltados para mulheres, no entanto, não é por acaso. Da mesma forma que a cultura terapêutica não se restringe à prática dos profissionais do campo psi (FUREDI, 2004; ROSE, 2007, 2008), a cultura da autoajuda não se propaga apenas através dos livros. Embora o mercado editorial continue sendo o principal responsável pela divulgação do imaginário associado a temas como autoaperfeiçoamento, autorrealização e busca por sucesso e felicidade, a mídia, principalmente nas duas últimas décadas, é palco de um fenômeno definido por Bauman (1998: 222) como um "surto do aconselhamento", caracterizado pela presença constante de experts em programas de televisão, de rádio e em colunas específicas de jornais e revistas que incorporam, com específicas adaptações, 0 tipo de linguagem apregoada pelos livros.

Uma das principais peculiaridades da autoajuda voltada para a consecução de uma vida bemsucedida dedicada ao público feminino é 0 destaque dado às relações amorosas. Enquanto nos livros para o público em geral, ou masculino, essa questão aparece de forma bastante periférica, acessória, no caso do discurso direcionado às mulheres, a conquista e a manutenção de um relacionamento amoroso aparecem como o eixo central, a partir do qual podem ser desenvolvidos outros setores da vida. Vale destacar que não me refiro aos livros que oferecem aconselhamentos afetivos, os quais compõem, certamente, o filão de autoajuda feminina mais profícuo, e, sim, aos que, teoricamente, se propõem a turbinar a carreira das leitoras.

Curiosamente, no livro Como alcançar o sucesso (MARDEN, 2011), publicado pela primeira vez em 1896, considerado um clássico do gênero, em uma das raras passagens em que se dedica a falar sobre o sexo feminino, Marden faz uma explanação que vai no sentido contrário ao que percebemos nos livros contemporâneos, especificamente neste que analiso neste artigo, relativo à questão carreira versus casamento. Em um capítulo dedicado ao tema da vocação e do talento, ele, em tom de repúdio, dirige-se a elas:

Se precisam ganhar dinheiro, ficam satisfeitas em ficar de pé atrás de um balcão, ou dar aulas ano após ano para a mesma série, enquanto os homens que se formaram com vocês sobem os degraus rumo a magistérios e melhores salários, e depois partam para o direito, a física, ou talvez o firmamento legislativo, ultrapassando todas as dificuldades e os obstáculos em seu caminho. Vocês, meninas, satisfeitas com a mediocridade, só têm olhos para a "grande chance": 0 casamento. Se você se casar com um homem rico - que significa casar bem, de acordo com o senso comum moderno -, você se veste mais elegantemente e cultiva um círculo de amizades de bom gosto, deixando que seu marido e seu pastor pensem por você, 
tornando-se, na economia da vida, uma pessoa suscetível e sem importância. Se você for fiel à grande paixão e aceitar com ela a pobreza, você cozinha, faz café, esfrega o chão, dá palmadas nas crianças e fala com sua vizinha por cima da cerca do quintal por diversão, passando os anos literalmente como um cavalo na esteira, tudo pela falta de propósito - um propósito suficientemente poderoso para converter 0 talento latente em uma pedra preciosa de beleza viva, uma força criativa que torna todos os adjuntos secundários, como planetas ao redor de seu Sol central. Escolha um caminho ou chamado e domine-o em todos os seus detalhes, e, se for coroada com um casamento, ele apenas adicionará uma nova glória a seu trabalho (MARDEN, 2011, p. 61-62).

Em que pese, dentre outras questões, a falta de consideração do autor ao contexto histórico que explica a diferença de status vivenciada entre mulheres e homens, que ele prefere atribuir unicamente a uma falta de empenho ou ambição feminina, e também o desdém reservado a algumas ocupações, é significativo que um livro escrito em 1896 seja mais incisivo ao falar sobre a relação entre trabalho e vida conjugal do que algumas publicações do início do século XXI.

Todas as comparações propostas pelas publicações contemporâneas usam como contraponto as questões conjugais. A competição por um cargo, por exemplo, aparece constantemente descrita como muito similar à luta pelo "homem ideal".

No mercado de trabalho, achar a vaga perfeita é o mesmo que encontrar o príncipe encantado montado num cavalo branco! Este é o sonho de toda mulher: um homem sem defeitos, uma fa- mília maravilhosa, o corpo sem celulite e o cargo de diretoria! Acorda, Cinderela! (SLEIMAN, 2008, p. 46).

A ordem em que os sonhos femininos são apresentados (homem $>$ família $>$ corpo $>$ trabalho) não me parece aleatória. 0 chamamento ao final do parágrafo ("Acorda, Cinderela!") dá a impressão de que a autora irá propor um questionamento a respeito de tais ideais que, segundo ela, conformariam a expectativa de boa vida do público feminino em geral. Não é, no entanto, o que ocorre. Logo no parágrafo seguinte, ela afirma:

Mas isso é possível sim... Em ambas as situações, a mulher deve procurar se destacar das concorrentes, causando sempre o impacto necessário para se fazer notar de forma positiva. Ter autoconfiança, desenvolver as habilidades, ter comprometimento, buscar qualificação e acima de tudo, perceber a importância do marketing pessoal (2008, p. 46).

É significativo, também, que os discursos

presentes nos livros de autoajuda abordem a questão familiar, principalmente a partir da concepção das famílias nucleares. De acordo com Gilberto Velho (1987), a ênfase nesse tipo de arranjo familiar ocorreu no período conhecido com o do Milagre Brasileiro, quando, em meio à vigência de uma ditadura militar (final dos anos 1960 e início da década de 1970), o país experimentou altas taxas de crescimento econômico. Conforme o autor, tal conjuntura histórica reforçava o projeto individualizante de família nuclear, a partir da ampla veiculação de uma propaganda que enfatizava o consumo 
e 0 sucesso material. É esse modelo de família que vai despontar como paradigma da sociedade capitalista moderna: a família que compra, viaja, investe... Velho (1987) argumenta que, paralelamente a esse momento, ocorreu 0 enfraquecimento dos laços sociais com um universo expandido de parentes, amigos e vizinhos. Os dois fenômenos, desse modo, podem ser explicados a partir de um mesmo movimento.

Ainda de acordo com Velho (1987), a ideologia do individualismo, dessa forma, pode ser percebida não apenas através do indivíduo biológico propriamente dito, mas, sim, também em sua relação com essa família nuclear, que está diretamente ligada a ele, em seus sucessos e fracassos. Essa situação, obviamente, é muito mais visível entre a classe média, que tem a possibilidade de habitar em casas e apartamentos separados, em moradias onde costumam viver apenas pais e filhos, ou, como vem ocorrendo com cada vez mais frequência, composições monoparentais.

\section{Considerações Finais}

Embora não seja, decerto, a única formadora da mentalidade contemporânea, a autoajuda desempenha um papel fundamental na produção da subjetividade a partir da qual avaliamos a pertinência de determinados papéis que vivenciamos socialmente. Neste artigo, como o foco recaiu sobre a autoajuda voltada para o público feminino, é particularmente notável a persistência de discursos que reiteram perspectivas que muitos julgam ultrapassadas em relação às questões de gênero.

0 livro que serviu de objeto a esta análise, longe de ser uma curiosidade acadêmica ou um exemplo anedótico, é um artefato cultural bastante eloquente do ethos difundido pela autoajuda. A associação, proposta pela obra, da mulher ao ambiente privado, como aquela que deve ter suas prioridades voltadas para a consecução de um relacionamento estável (com um homem) e de uma família nuclear tradicional aparece lado a lado com as demandas contemporâneas sobre 0 sucesso no mundo do trabalho. Se hoje a competição é entendida como um modo de vida inquestionável, no caso das mulheres ela ganha ares biologizantes, com referências explícitas à presença de hormônios e inclinações quase geneticamente determinadas, que remontariam à experiência imemorial de luta por um parceiro. Tal familiaridade com 0 ambiente competitivo, no entanto, não é entendida pela autora como uma vantagem comparativa em tempos de sucesso imperativo, afinal, a conduta das mulheres nessas disputas seria marcada, também, pela questão da falta de controle sobre seus atos e suas emoções.

Dessa maneira, percebemos a manutenção de asseverações bastante problemáticas em relação ao discurso sobre 0 ideal de "mulher vencedora". 0 questionamento à ideia de divisão dos indivíduos em categorias como vencedores e fracassados serviu de principal motivação 
para 0 desenvolvimento da pesquisa mais ampla na qual este artigo se insere. Nossa concepção, entretanto, é a de que as premissas e formulações que caracterizam 0 atual momento social, que classificamos como marcado pelo "imaginário do sucesso", ganham contornos ainda mais complexos quando pensadas quanto às demandas feitas às mulheres. Tais perspectivas, desse modo, associam, por um lado, o que há de mais questionável em termos de indução a uma vitória ancorada, sobretudo, na prosperidade financeira e nos atos de consumo e, por outro, retomam abordagens muito conservadoras em relação a temas como sexualidade e comportamento.

\section{Referências}

BAUMAN, Zygmunt. 0 mal-estar da pósmodernidade. Rio de Janeiro: Jorge Zahar, 1998. BRUNELLI, Anna Flora. Estereótipos da mulher no discurso de autoajuda. Cadernos de Linguagem e Sociedade, v. $13, \mathrm{n}^{\circ} 2,2012$.

CASTELLANO, Mayka. Da importância do caráter ao imperativo da vitória: as transformações na literatura de autoajuda do século XIX aos dias atuais. Anais do $4^{0}$ Congresso Internacional em Comunicação e Consumo Comunicon. São Paulo, 2014.

CATANO, James V. Ragged dicks. Masculinity, steel, and the rhetoric of the self-made man. Carbondale and Edwardsville : Southern Illinois University Press, 2001.

DECKER, Jeffrey Louis. Made in America. Self-styled success from Horatio Alger to Oprah Winfrey.

Minneapolis: University of Minnesota Press, 1997.

EHRENBERG, Alain. Le culte de la performance.

Paris: Calmann-Lévy, 1991.
FOUCAULT, Michel. A "governamentalidade". In: MOTTA, M. B. (org.) Estratégia, poder-saber. Ditos e escritos: vol. 4. Rio de Janeiro: Forense Universitária, 2006, p. 281-305.

. A ordem do discurso. São Paulo: Loyola, 1999. . 0 sujeito e o poder. In: DREYFUS, $H$. \& RABINOW, P. (orgs.). Michel Foucault, uma trajetória filosófica: para além do estruturalismo e da hermenêutica. Rio de Janeiro: Forense Universitária, 1995, p. 231-249.

FREIRE FILHO, João. Reinvenções da resistência juvenil: os estudos culturais e as micropolíticas do cotidiano. Rio de Janeiro: Mauad X, 2007.

FUREDI, Frank. Therapy culture. Cultivating vulnerability in an uncertain age. Londres: Routledge, 2004.

GEERTZ, Clifford. A interpretação das culturas. Rio de Janeiro: Jorge Zahar, 1978.

MARDEN, Orison Swett. Como alcançar o sucesso. São Paulo: Rai, 2011 [1896].

McGEE, Micki. Self-Help, Inc. Makeover culture in American life. Nova York: Oxford University Press, 2005.

McR0BBIE, Angela. Pós-feminismo e cultura popular: Bridget Jones e o novo regime de gênero. Cartografias Estudos Culturais e Comunicação, Porto Alegre, 2006.

PRADO, José Luiz Aidar. Convocações biopolíticas dos dispositivos comunicacionais. São Paulo: EDUC: FAPESP, 2013.

ROSE, Nikolas. Powers of freedom. Cambridge: Cambridge University Press, 1999.

The politics of life itself: biomedicine, power, and subjectivity in the twenty-first century. Princeton: Princeton University Press, 2007. 
Psicologia como uma ciência social.

Psicologia \& Sociedade, n. 20, v. 2, p.155-164, 2008.

SENNETT, Richard. A corrosão do caráter.

Consequências pessoais do trabalho no novo

capitalismo. Rio de Janeiro: Record, 2007.

SLEIMAN, Fádua. Marketing de B.A.T.O.M. Atitudes

que fazem da mulher uma vencedora! Curitiba:

Coração Brasil, 2008.

SMILES, Samuel. Ajude-se. São Paulo: Rai, 2012

[1859].

VELHO, Gilberto. Individualismo e cultura.

Notas para uma antropologia da sociedade

contemporânea. Rio de Janeiro: Jorge Zahar, 1987. 


\section{"Be a winner woman!":} gender peculiarities and success definitions on self-help literature

\section{Abstract}

In this paper, from the poststructuralistinspired discourse analysis, I evaluate a book of self-help literature dedicated to female success. The reading of the book Marketing de B.A.T.O.M: atitudes que fazem da mulher uma vencedora (Fádua Sleiman, 2008) allows us to verify the existence of typical demands of the contemporary imaginary of success, that urge all to be winners, while that provides indications that, when referring specifically to women, these books point to a series of problematic continuities concerning gender issues and the inclusion of women in the labor market.

\section{Keywords}

Self-help. Sucess. Gender.
"Sea una mujer vencedora!": particularidades de género y definiciones del éxito en la literatura de autoayuda

\section{Resumen}

En este trabajo, a partir del análisis del discurso de inspiración postestructuralista, evalúo un ejemplar de la literatura de autoayuda dedicado al éxito femenino. La lectura del libro Marketing de Batom: atitudes que fazem da uma mulher vencedora (Fádua Sleiman, 2008) nos permite verificar la existencia de exigencias típicas del imaginario contemporáneo del éxito, que insta a todos a que sean "vencedores", mientras que proporciona indicios de que, cuando se refieren específicamente a las mujeres, estos libros apuntan a una serie de continuidades problemáticas relativas a las cuestiones de género y a la inclusión de las mujeres en el mercado laboral.

Palabras clave

Autoayuda. Éxito. Género. 


\section{Expediente}

A revista E-Compós é a publicação científica em formato eletrônico da Associação Nacional dos Programas de Pós-Graduação em Comunicação (Compós). Lançada em 2004, tem como principal finalidade difundir a produção acadêmica de pesquisadores da área de Comunicação, inseridos em instituições do Brasil e do exterior.

\section{E-COMPÓS I www.e-compos.org.br I E-ISSN 1808-2599}

Revista da Associação Nacional dos Programas de Pós-Graduação em Comunicação.

Brasília, v.18, n.2, maio/ago. 2015.

A identificação das edições, a partir de 2008, passa a ser volume anual com três números.

Indexada por Latindex I www.latindex.unam.mx

\section{CONSELHO EDITORIAL}

Alexandre Rocha da Silva, Universidade Federal do Rio Grande do Sul, Brasil Alexandre Farbiarz, Universidade Federal Fluminense, Brasil Ana Carolina Damboriarena Escosteguy, Pontifícia Universidade Católica do Rio Grande do Sul, Brasil

Ana Carolina Rocha Pessôa Temer, Universidade Federal de Goiás, Brasil Ana Regina Barros Rego Leal, Universidade Federal do Piauí, Brasil André Luiz Martins Lemos, Universidade Federal da Bahia, Brasil Andrea França, Pontifícia Universidade Católica do Rio de Janeiro, Brasil Antonio Carlos Hohlfeldt, Pontifícia Universidade Católica do Rio Grande do Sul, Brasil

Arthur Ituassu, Pontifícia Universidade Católica do Rio de Janeiro, Brasil Álvaro Larangeira, Universidade Tuiuti do Paraná, Brasil Ângela Freire Prysthon, Universidade Federal de Pernambuco, Brasil César Geraldo Guimarães, Universidade Federal de Minas Gerais, Brasil Cláudio Novaes Pinto Coelho, Faculdade Cásper Líbero, Brasil Daisi Irmgard Vogel, Universidade Federal de Santa Catarina, Brasil Daniela Zanetti, Universidade Federal do Espírito Santo, Brasil Denize Correa Araujo, Universidade Tuiuti do Paraná, Brasil Eduardo Antonio de Jesus, Pontifícia Universidade Católica de Minas Gerais, Brasil

Eduardo Vicente, Universidade de São Paulo, Brasil

Elizabeth Moraes Gonçalves, Universidade Metodista de São Paulo, Brasil Erick Felinto de Oliveira, Universidade do Estado do Rio de Janeiro, Brasil Francisco Elinaldo Teixeira, Universidade Estadual de Campinas, Brasil Francisco Paulo Jamil Almeida Marques, Universidade Federal do Ceará, Brasil Gabriela Reinaldo, Universidade Federal do Ceará, Brasil Gisela Grangeiro da Silva Castro, Escola Superior de Propaganda e Marketing, Brasil

Goiamérico Felício Carneiro Santos, Universidade Federal de Goiás, Brasil Gustavo Daudt Fischer, Unisinos, Brasil

Herom Vargas, Universidade Municipal de São Caetano do Sul, Brasil
Itania Maria Mota Gomes, Universidade Federal da Bahia, Brasil Janice Caiafa, Universidade Federal do Rio de Janeiro, Brasil Jiani Adriana Bonin, Universidade do Vale do Rio dos Sinos, Brasil José Afonso da Silva Junior, Universidade Federal de Pernambuco, Brasil José Luiz Aidar Prado, Pontifícia Universidade Católica de São Paulo, Brasil Kati Caetano, Universidade Tuiuti do Paraná, Brasil

Lilian Cristina Monteiro França, Universidade Federal de Sergipe, Brasil

Liziane Soares Guazina, Universidade de Brasília, Brasil Luíza Mônica Assis da Silva, Universidade de Caxias do Sul, Brasil Luciana Miranda Costa, Universidade Federal do Pará, Brasil Malena Segura Contrera, Universidade Paulista, Brasil Marcel Vieira Barreto Silva, Universidade Federal da Paraíba, Brasil Maria Ogécia Drigo, Universidade de Sorocaba, Brasil Maria Ataide Malcher, Universidade Federal do Pará, Brasil Maria Clotilde Perez Rodrigues, Universidade de São Paulo, Brasil Maria das Graças Pinto Coelho, Universidade Federal do Rio Grande do Norte, Brasil

Mauricio Ribeiro da Silva, Universidade Paulista, Brasil

Mauro de Souza Ventura, Universidade Estadual Paulista, Brasil

Márcio Souza Gonçalves, Universidade do Estado do Rio de Janeiro, Brasil Micael Maiolino Herschmann, Universidade Federal do Rio de Janeiro, Brasil Mirna Feitoza Pereira, Universidade Federal do Amazonas, Brasil Nísia Martins Rosario, Universidade Federal do Rio Grande do Sul, Brasil Potiguara Mendes Silveira Jr, Universidade Federal de Juiz de Fora, Brasil Regiane Ribeiro, Universidade Federal do Paraná, Brasil Rogério Ferraraz, Universidade Anhembi Morumbi, Brasil Rose Melo Rocha, Escola Superior de Propaganda e Marketing, Brasil Rozinaldo Antonio Miani, Universidade Estadual de Londrina, Brasil Sérgio Luiz Gadini, Universidade Estadual de Ponta Grossa, Brasil Simone Maria Andrade Pereira de Sá, Universidade Federal Fluminense, Brasil Veneza Mayora Ronsini, Universidade Federal de Santa Maria, Brasil Walmir Albuquerque Barbosa, Universidade Federal do Amazonas, Brasil

\section{COMISSÃO EDITORIAL}

\section{Cristiane Freitas Gutfreind}

Pontifícia Universidade Católica do Rio Grande do Sul, Brasil

Irene Machado

Universidade de São Paulo, Brasil

Jorge Cardoso Filho

Universidade Federal do Reconcavo da Bahia, Brasil

Universidade Federal da Bahia, Brasil

\section{EQUIPE TÉCNICA}

ASSISTENTE EDITORIAL I Márcio Zanetti Negrini

REVISÃO DE TEXTOS I Press Revisão

EDITORAÇÃO ELETRÔNICA I Roka Estúdio

CONTATO I revistaecompos@gmail.com
COMPóS I www.compos.org.br

Associação Nacional dos Programas de Pós-Graduação em Comunicação

Presidente

Edson Fernando Dalmonte

Programa de Pós-Graduação em Comunicação

e Cultura Contemporânea - UFBA

edsondalmonte@uol.com.br

Vice-presidente

Cristiane Freitas Gutfreind

Programa de Pós-Graduação em Comunicação Social - PUC-RS cristianefreitas@pucrs.br

Secretário-Geral

Rogério Ferraraz

Programa de Pós-Graduação em Comunicação

Universidade Anhembi Morumbi

rogerioferraraz@anhembimorumbi.edu.br 